\title{
Chlamyphilone, a Novel Pochonia chlamydosporia Metabolite with Insecticidal Activity
}

\author{
Federica Lacatena ${ }^{1, \dagger}{ }^{,}$Roberta Marra ${ }^{1, \dagger}{ }^{+}$Pierluigi Mazzei ${ }^{2,3}{ }^{(0)}$, Alessandro Piccolo ${ }^{1,3}$, \\ Maria Cristina Digilio ${ }^{1}$ (), Massimo Giorgini ${ }^{4}{ }^{-}$, Sheridan L. Woo ${ }^{4,5}$, Pierpaolo Cavallo ${ }^{6,7}$, \\ Matteo Lorito ${ }^{1,4}$ and Francesco Vinale ${ }^{1,4, * \text { (D) }}$ \\ 1 Dipartimento di Agraria, Università degli Studi di Napoli Federico II, 80055 Portici (NA), Italy; \\ federica.lacatena@unina.it (F.L.); robmarra@unina.it (R.M.); alessandro.piccolo@unina.it (A.P.); \\ digilio@unina.it (M.C.D.); lorito@unina.it (M.L.) \\ 2 Dipartimento di Farmacia (DIFARMA), Università degli Studi di Salerno, 84084 Fisciano (SA), Italy; \\ pmazzei@unisa.it \\ 3 Centro Interdipartimentale di Ricerca sulla Spettroscopia di Risonanza Magnetica Nucleare, per l'Ambiente, \\ l'Agro-Alimentare ed i Nuovi Materiali (CERMANU), Università degli Studi di Napoli Federico II, \\ 80055 Portici (NA), Italy \\ 4 Istituto per la Protezione Sostenibile delle Piante, Consiglio Nazionale delle Ricerche (IPSP-CNR), \\ 80055 Portici (NA), Italy; massimo.giorgini@ipsp.cnr.it (M.G.); woo@unina.it (S.L.W.) \\ 5 Dipartimento di Farmacia, Università degli Studi di Napoli Federico II, 80131 Napoli, Italy \\ 6 Dipartimento di Fisica "E.R. Caianiello", Università degli Studi di Salerno, 84084 Fisciano (SA), Italy; \\ pcavallo@unisa.it \\ 7 Istituto Sistemi Complessi, Consiglio Nazionale delle Ricerche (ISC-CNR), 00185 Rome, Italy \\ * Correspondence: francesco.vinale@ipsp.cnr.it; Tel.: +39-081-253-9338 \\ $\dagger$ These authors contributed equally to this work.
}

Academic Editor: Josphat Matasyoh

Received: 14 January 2019; Accepted: 14 February 2019; Published: 19 February 2019

check for updates

\begin{abstract}
Metabolites from a collection of selected fungal isolates have been screened for insecticidal activity against the aphid Acyrthosiphon pisum. Crude organic extracts of culture filtrates from six fungal isolates (Paecilomyces lilacinus, Pochonia chlamydosporia, Penicillium griseofulvum, Beauveria bassiana, Metarhizium anisopliae and Talaromyces pinophilus) caused mortality of aphids within $72 \mathrm{~h}$ after treatment. In this work, bioassay-guided fractionation has been used to characterize the main bioactive metabolites accumulated in fungal extracts. Leucinostatins A, B and D represent the bioactive compounds produced by P. lilacinus. From P. griseofulvum and B. bassiana extracts, griseofulvin and beauvericin have been isolated, respectively; 3-O-Methylfunicone and a mixture of destruxins have been found in the active fractions of T. pinophilum and M. anisopliae, respectively. A novel azaphilone compound, we named chlamyphilone, with significant insecticidal activity, has been isolated from the culture filtrate of $P$. chlamydosporia. Its structure has been determined using extensive spectroscopic methods and chemical derivatization.
\end{abstract}

Keywords: secondary metabolites; beneficial microbes; pea aphid; azaphilones

\section{Introduction}

Alarm over the impact of pesticides on the environment and human health is increasing year after year, and rigorous pesticide registration procedures have been introduced. Through Directive 2009/128/EC, the European Community has severely restricted the use of synthetic pesticides in plant protection, and the new regulations have reduced the number of chemicals available in agriculture [1]. Novel pesticides, including natural product-based formulations, have been developed to counteract the evolution of resistance among plant pathogen and pest populations [2]. 
Microorganisms biosynthesize thousands of compounds displaying different biological activities, e.g., acting as antibiotics, therapeutic agents, toxins, hormones, etc. [3]. Thus, the exploitation of the microbial metabolome has become an important area of research to isolate novel natural products potentially useful for agricultural applications [3]. The improvement of screening technologies can be used to extend the search of new microbial active metabolites, i.e., through (i) upgrading of fermentation techniques, (ii) the development of new methods for detection, and (iii) genetic manipulation to create mutants able to produce qualitatively or quantitatively different metabolites [4].

Microorganisms have been extensively screened for antibiotic production; the main producers are fungi and bacteria, particularly the actinomycetes Streptomyces spp. [5]. A large number of manuscripts deal with microbial metabolites, which have demonstrated efficacy as crop protection agents, but only a few compounds have been marketed so far [2]. Examples of commercially available microbial metabolites with insecticide activity are: (1) abamectin and anthelmintic produced by the soil-dwelling actinomycete S. avermitilis; (2) milbemycin (also known as milbemectin), an insecticide and acaricide from S. hygroscopicus subsp. aureolacrimosus; (3) polynactins, secondary metabolites from the actinomycete $S$. aureus, isolated and applied as a mixture of tetranactin, trinactin and dynactin; (4) spinosad, a secondary metabolite from the soil actinomycete Saccharopolyspora spinosa [2].

The interaction between some fungal strains and the plant establish a molecular cross-talk in which fungal metabolites can act as elicitors that activate the expression of genes involved in plant defence response, and promote the growth of the plant [6]. Identification of new bioactive compounds may be obtained with a good microbial collection or isolating metabolites not expressed under standard laboratory conditions [6-8].

In this work, we show the results of a screening aimed to isolate microbial metabolites with insecticidal activity. Various genera of fungi, including some entomopathogenic species, were grown in liquid culture and their major secondary metabolites were investigated. Bioassay-guided fractionation used to isolate the bioactive metabolites allowed the identification of seven known compounds and a new metabolite named chlamyphilone. This compound was fully characterized by spectrometric analysis and chemical derivatization. The fungal metabolites have been screened for insecticidal activity against Acyrthosiphon pisum (Hemiptera: Aphididae), the pea aphid, whose high rate of increase makes it a useful model for screening [9].

\section{Results}

The microbes used in the present study includes various genera of fungi identified according to morphological features and molecular analyses (rDNA-ITS and $\beta$-tubulin gene sequencing). In particular, 5 isolates belong to the Trichoderma genus (T. tomentosum F19, T. asperellum CINO1, T. harzianum M10, T. harzianum F53, T. velutinum F28) and 4 to Penicillium (P. chrysogenum F5, P. decumbens F29, P. griseofulvum F11, P. restrictum F55). Beauveria bassiana BB1, Chloridium virescens F57, Metarhizium anisopliae MA3, Paecilomyces lilacinus 100379, Pochonia chlamydosporia B and Talaromyces pinophilus F36CF are present as single species.

All fungi have been grown in static conditions and the culture filtrates were extracted exhaustively with ethyl acetate. The crude extracts were fractionated by column chromatography to provide a total of 79 organic fractions. The extracts and all the fractions were tested at different concentrations on Acyrthosiphon pisum. Table 1 reports the percentage of mortality at $72 \mathrm{~h}$ of the active extracts/fractions obtained from different fungal isolates. Only extracts obtained from P. lilacinus, P. griseofulvum, P. chlamydosporia, B. bassiana, M. anisopliae and T. pinophilus showed significant insecticidal activity (data obtained from the other fungal strains are not showed). Moreover, the bioassay-guided fractionation indicated that only one fraction per strain was responsible of a significant aphid mortality after $72 \mathrm{~h}$ exposure (Table 1 ).

Chemical characterization of the active fractions was obtained using NMR and/or LC-MS qTOF analyses. Fraction No. 3 of P. lilacinus (showing 30\% aphid mortality; Table 1) was constituted by a 
mixture of leucinostatins A, B and D (1, 2 and 3, respectively; Figure 1), with the molecular weights (MW) $1218.634 \mathrm{~g} / \mathrm{mol}, 1204.607 \mathrm{~g} / \mathrm{mol}$ and $1104.4799 \mathrm{~g} / \mathrm{mol}$, respectively (Figure S1).

Table 1. Insecticidal activity of fungal organic extracts and active fractions as mortality (\%) of the pea aphid Acyrthosiphon pisum at $72 \mathrm{~h}$ after exposure. Different lower letters refer to significant differences $(p<0.05)$ among treatments at the same incubation time. Extracts from T. tomentosum F19, T. asperellum CINO1, T. harzianum M10, T. harzianum F53, T. velutinum F28, P. chrysogenum F5, P. decumbens F29, $P$. restrictum $\mathrm{F} 55$ and $C$. virescens $\mathrm{F} 57$ did not show significant insecticidal activity.

\begin{tabular}{|c|c|c|c|c|c|}
\hline Microbes & $\begin{array}{l}\text { Aphid Mortality }(\%) \\
\text { at } 72 \mathrm{~h} \text { after } \\
\text { Exposure to Organic } \\
\text { Extract }(10 \mathrm{mg} / \mathrm{mL})\end{array}$ & $\begin{array}{l}\text { Standard } \\
\text { Deviation }\end{array}$ & $\begin{array}{l}\text { Active } \\
\text { Fraction } \\
\text { (Number) }\end{array}$ & $\begin{array}{c}\text { Aphid Mortality (\%) } \\
\text { at } 72 \mathrm{~h} \text { after Exposure } \\
\text { to Active Fraction } \\
(0.5 \mathrm{mg} / \mathrm{mL})\end{array}$ & $\begin{array}{l}\text { Standard } \\
\text { Deviation }\end{array}$ \\
\hline $\begin{array}{l}\text { Paecilomyces } \\
\text { lilacinus }\end{array}$ & $6.0^{\mathrm{a}}$ & \pm 3.6 & 3 & $30.0^{a}$ & \pm 18.0 \\
\hline $\begin{array}{l}\text { Penicillium } \\
\text { griseofulvum }\end{array}$ & $63.3^{b}$ & \pm 21.0 & 7 & $73.3^{b}$ & \pm 8.0 \\
\hline $\begin{array}{c}\text { Pochonia } \\
\text { chlamydosporia }\end{array}$ & $50.0^{b}$ & \pm 13.0 & 2 & $100.0^{\mathrm{c}}$ & \pm 0.0 \\
\hline $\begin{array}{l}\text { Beuveria } \\
\text { bassiana }\end{array}$ & $40.0^{\mathrm{b}}$ & \pm 17.0 & 3 & $40.0^{a}$ & \pm 22.9 \\
\hline $\begin{array}{l}\text { Metarhizium } \\
\text { anisopliae }\end{array}$ & $53.3^{b}$ & \pm 5.7 & 5 & $60.0^{\mathrm{a}}$ & \pm 10.0 \\
\hline $\begin{array}{l}\text { Talaromyces } \\
\text { pinophilus }\end{array}$ & $65.0^{\mathrm{b}}$ & \pm 15.0 & 2 & $48.3^{a}$ & \pm 5.8 \\
\hline
\end{tabular}

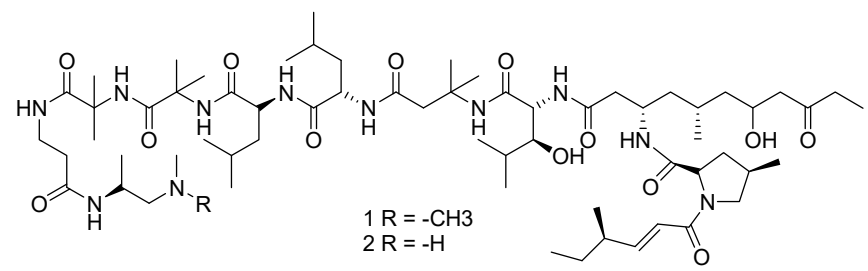

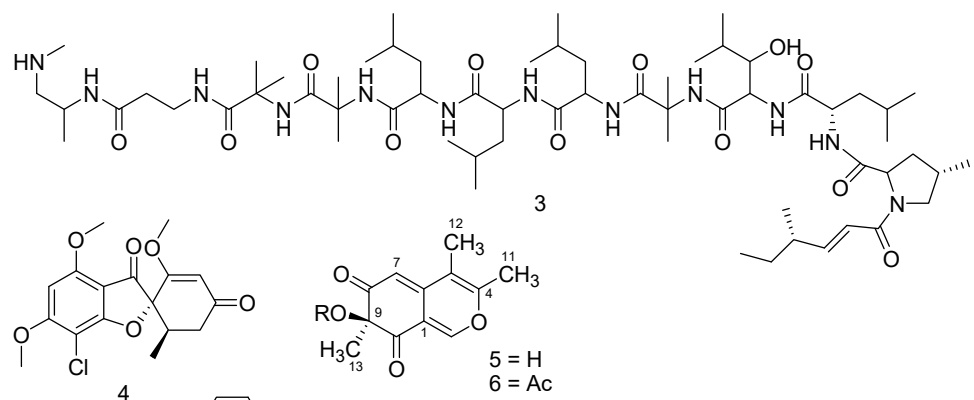

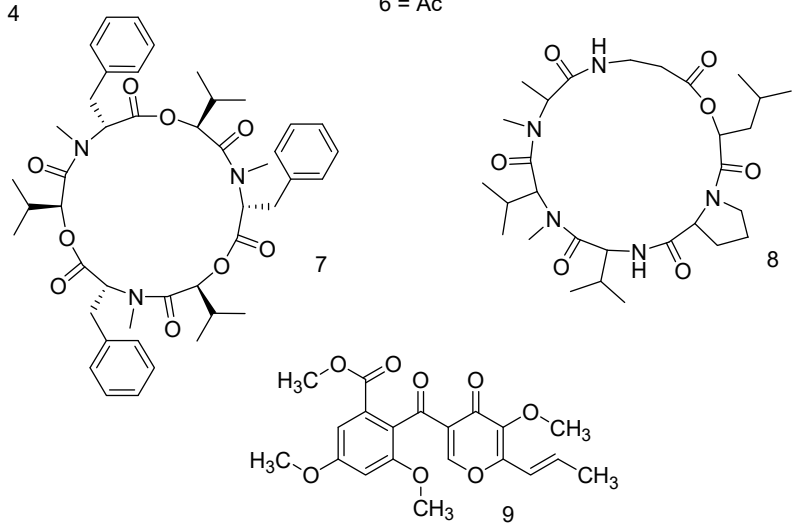

Figure 1. Chemical structures of leucinostatin A, 1; leucinostatin B, 2; leucinostatin D, 3; griseofulvin, 4; chlamyphilone, 5; Ac-chlamyphilone, 6; beauvericin, 7; dextrusin B2, 8; 3-O-Methylfunicone, 9. 
The mycotoxin griseofulvin (4 in Figure 1) was determined as the main metabolite of P. griseofulvum and was isolated in the active fraction number 7 (showing 73,3\% aphid mortality; Table 1). Figure S3 reports the mass spectrum of the isolated compound.

The residue recovered after the organic extraction $(350 \mathrm{mg})$ of $P$. chlamydosporia culture filtrate was subjected to flash column chromatography, eluting with $\mathrm{CH}_{2} \mathrm{Cl}_{2} / \mathrm{MeOH}$ (90:10 v/v). Fractions showing similar thin-layer chromatography (TLC) profiles were combined and further purified by using preparative TLC separation ( $\mathrm{Si}$ gel; $\mathrm{CH}_{2} \mathrm{Cl}_{2} / \mathrm{MeOH}$ 90:10 v/v). Both fractions and pure compounds were tested for insecticidal activity. Twelve milligrams of a novel compound, named chlamyphilone (5 in Figure 1; $5 \mathrm{mg} / \mathrm{L}$ ), were obtained as a yellow amorphous solid in pure form after TLC (Rf in $\left.\mathrm{CH}_{2} \mathrm{Cl}_{2} / \mathrm{MeOH} 90: 10 \mathrm{v} / \mathrm{v}=0.8\right)$ and has: $[\alpha]^{25} \mathrm{D}-21.9^{\circ}\left(\mathrm{c} 1 ; \mathrm{CH}_{2} \mathrm{Cl}_{2}\right) ; \mathrm{UV}\left(\mathrm{CH}_{2} \mathrm{Cl}_{2}\right) \lambda \max (\log \varepsilon)$ 219 (3.57), 332 (4.23). ${ }^{1} \mathrm{H}$ and ${ }^{13} \mathrm{C}$ NMR spectral data of chlamyphilone (in $\mathrm{CDCl}_{3}$ ) are presented in Table 2. LC-MS qTOF analysis detected the precursor ions at $m / z 221.0814$ (pseudomolecular ion

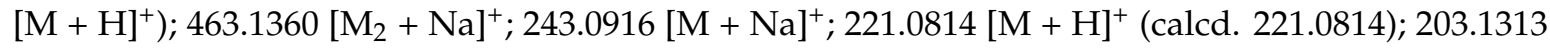
$\left[\mathrm{M}+\mathrm{H}-\mathrm{H}_{2} \mathrm{O}\right]^{+}$(Figure S4). The results obtained by ${ }^{13} \mathrm{C}$ NMR (Table 2 and Figure S6) and LC-MS qTOF analyses (Figure S4) were consistent with a compound having a molecular weight of 220.0814, corresponding to the molecular formula $\mathrm{C}_{12} \mathrm{H}_{12} \mathrm{O}_{4}$ with seven unsaturations.

Table 2. ${ }^{1} \mathrm{H}$ and ${ }^{13} \mathrm{C}$ NMR spectral data of chlamyphilone (in $\mathrm{CDCl}_{3}$ ).

\begin{tabular}{cccc}
\hline Position & $\boldsymbol{\delta}_{\mathbf{C}}$ Mult. & $\boldsymbol{\delta}_{\mathbf{H}}(\boldsymbol{J}$ in Hz$)$ & HMBC * \\
\hline 1 & $115.3 \mathrm{qC}$ & & \\
2 & $151.7 \mathrm{CH}$ & $7.91 \mathrm{~d}(1.37)$ & $1,10,11$ \\
4 & $155.1 \mathrm{qC}$ & & \\
5 & $114.4 \mathrm{qC}$ & & \\
6 & $145.2 \mathrm{qC}$ & & \\
7 & $102.9 \mathrm{CH}$ & $5.55 \mathrm{~d}(1.37)$ & 6,9 \\
8 & $196.3 \mathrm{qC}$ & & \\
9 & $83.1 \mathrm{qC}$ & & \\
10 & $196.5 \mathrm{qC}$ & & \\
11 & $17.5 \mathrm{CH}_{3}$ & $2.26 \mathrm{~d}(0.6)$ & 2 \\
12 & $12.7 \mathrm{CH}_{3}$ & $1.93 \mathrm{~d}(0.6)$ & 4,6 \\
13 & $28.6 \mathrm{CH}_{3}$ & $1.55 \mathrm{~s}$ & $9,10,8$ \\
OH & & 3.9 & 8
\end{tabular}

* All correlations represent 2 or 3 bond couplings. Abbreviation, s: singlet, d: doublet, t: triplet, dd: doublet of doublets.

The UV spectrum showed absorption peaks characteristic of the azaphilone family, which are natural products containing a $6 H$-isochromene-6,8(7H)-dione. Six carbon signals at 102.9, 114.4, 115.3, 145.2, 151.7, and 155.1 ppm revealed three double bonds, whereas signals at 196.3 and 196.5 ppm indicated the presence of two ketones. The other four signals in the ${ }^{13} \mathrm{C}$ spectrum were all shifted upfield in the 12.7-83.11 ppm range. The DEPT data demonstrated that one of the protons in the molecule is bound to oxygen, and that in the molecule there are three $\mathrm{CH}_{3}$, two $\mathrm{CH}$, and seven fully substituted $\mathrm{C}$ atoms. The ${ }^{1} \mathrm{H}-{ }^{1} \mathrm{H}$ COSY, HSQC analysis, and the chemical shift evaluation (Table 2) allowed the identification of the structural fragment. In Table 2 all the compound signals are reported.

The connectivity of the spin systems was deduced by a long-range ${ }^{1} \mathrm{H}-{ }^{13} \mathrm{C}$ heterocorrelated experiment that was obtained with the HMBC (Table 2). In particular, the most relevant HMBC correlations are reported in Figure 2, which implied that the structure of the metabolite 5 is 7-hydroxy-3,4,7-trimethyl-isochromene-6,8-dione. The configuration of chlamyphilone was evident from NOESY experiment. The MM-2 energy calculation $(16.0 \mathrm{Kcal} / \mathrm{mol})$ was run to find the most stable conformational model (Figure S12). 


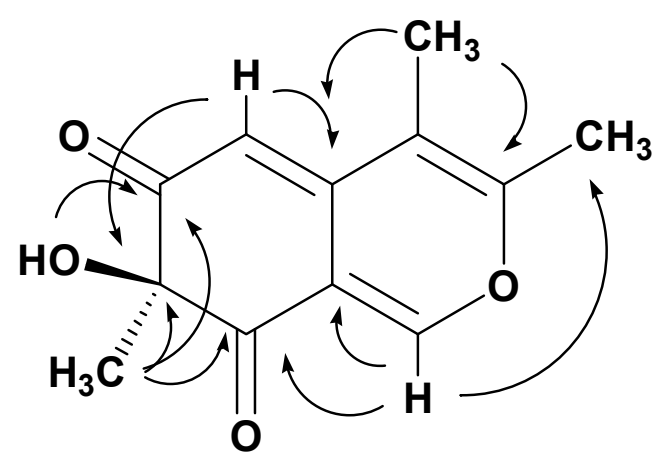

Figure 2. HMBC correlation of chlamyphilone.

To confirm the proposed structure, a sample of chlamyphilone was acetylated using acetic anhydride/pyridine (6 in Figure 1). The ${ }^{1} \mathrm{H}-\mathrm{NMR}$ spectrum of the product (acetic acid 3,4,7-trimethyl-6,8-dioxo-7,8-dihydro-6H-isochromen-7-yl ester) contained one acetate resonance, confirming the presence of the hydroxyl group bound to the carbon at 83.1. The ${ }^{13} \mathrm{C}-\mathrm{NMR}$ spectrum contained an additional signal for the acetyl carbonyl resonance at 170.8 and for the acetate methyl carbon at $18.4 \mathrm{ppm}$.

Chlamyphilone (5 in Figure 1) showed the highest insecticidal activity against Acyrthosiphon pisum with a median Lethal Dose (LD50) of $175 \mu \mathrm{g} / \mathrm{mL}$ and a minimal inhibitory concentration (MIC) of $150 \mu \mathrm{g} / \mathrm{mL}$ (Table 3).

Table 3. Insecticidal activity of chlamyphilone 5 at different concentrations. Treatments were evaluated as mortality (\%) of the pea aphid Acyrthosiphon pisum at $72 \mathrm{~h}$ after exposure to 5.

\begin{tabular}{ccc}
\hline Concentrations $(\boldsymbol{\mu g} / \mathbf{m L})$ & Aphid Mortality (\%) & Standard Deviation \\
\hline 500 & 100.0 & \pm 0.0 \\
200 & 100.0 & \pm 0.0 \\
190 & 96.7 & \pm 5.8 \\
180 & 51.7 & \pm 2.9 \\
170 & 30.0 & \pm 5.0 \\
160 & 8.3 & \pm 2.9 \\
150 & 3.3 & \pm 2.8 \\
\hline
\end{tabular}

The insecticidal activity of the B. bassiana strain used in the present work was mainly dependent on the presence of beauvericin ( 7 in Figure 1 ). This metabolite is a cyclohexadepsipeptide mycotoxin with the molecular formula $\mathrm{C}_{45} \mathrm{H}_{57} \mathrm{~N}_{3} \mathrm{O}_{9}$ (Figure S13).

From M. anisopliae extract, destruxin B2 has been characterized (8 in Figure 1). Destruxins are cyclic hexadepsipeptides composed of an $\alpha$-hydroxy acid and five amino acid residues. Individual destruxins differ in terms of the hydroxy acid, $\mathrm{N}$-methylation, and $\mathrm{R}$ group of the amino acid residues. Destruxin $\mathrm{B} 2$ has the molecular formula $\mathrm{C}_{29} \mathrm{H}_{49} \mathrm{~N}_{5} \mathrm{O}_{7}$, as revealed by the MS spectrum (Figure S14).

Finally, the major active metabolite produced by $T$. pinophilus strain F36CF was 3-O-methylfunicone (OMF—9 in Figure 1), a well-known $\gamma$-pyrone derivative, previously isolated from Talaromyces spp.

\section{Discussion}

In this work, a functional screening of fungal strains, preliminarily selected because of their ability to synthetize active metabolites, has been carried out. Bioassay-guided fractionation has been used to isolate microbial metabolites with insecticidal activity against the pea aphid A. pisum (Hemiptera: Aphididae), long used as a model to study plant-insect interactions [9]. This aphid is an important pest of several plants, is a phloem-feeding insect determining direct negative effects on plants in terms of 
nutritive subtraction and injection of toxic saliva. Moreover, it has been involved in the transmission of diverse plant viruses [9].

The active fraction obtained from P. lilacinus was constituted by a mixture of leucinostatins A, B, and D. Leucinostatins are peptides containing an unsaturated fatty acid, nine amino acid residues, and a basic component joined together by amide linkages [10]. These antibiotic metabolites also showed antitumor and nematocidal activities and an uncoupling effect on rat liver mitochondrial function $[10,11]$. To the best of our knowledge, our work is the first report on the insecticidal activity of leucinostatins against $A$. pisum.

Griseofulvin was determined to be the main metabolite of P. griseofulvum. The insecticidal activity of this metabolite has been previously demonstrated in the corn earworm, Helicoverpa zea Boddie, and the fall armyworm, Spodoptera frugiperda (J. E. Smith), by oral administration in an artificial diet (250 ppm) [12-14]. In the case of soft-tegument aphids like A. pisum, the activity is probably topical as oral administration may be excluded because of their peculiar feeding pattern. In fact, aphids use their piercing, sucking mouthparts to feed on plant fluid [9].

The extract of $P$. chlamydosporia culture filtrate yielded $12 \mathrm{mg}$ of a novel compound named chlamyphilone. This metabolite belongs to the class of azaphilones, which contain a $6 \mathrm{H}$-isochromene-6,8(7H)-dione or an isoquinoline-6,8(2H,7H)-dione skeleton (and its substituted derivatives thereof). This is the first report on the isolation of an azaphilone metabolite from P. chlamydosporia. A similar azaphilone, named myxostiol, with plant growth regulating activity, has been previously isolated from Myxotrichum stipitatum [15]. Over 170 different azaphilone compounds, classified into 10 structural groups, have been isolated from fungi belonging to 23 genera [16]. Azaphilones display a wide range of biological activities, such as antimicrobial, antifungal, antiviral, antioxidant, cytotoxic, nematocidal, and anti-inflammatory [16]. Many of these properties may be explained by the reactions of azaphilones with amino groups, such as those found in amino acids, proteins, and nucleic acids, resulting in the formation of vinylogous c-pyridones [16-18]. To the best of our knowledge, this is the first evidence of the insecticidal activity of a metabolite belonging to the class of azaphilones. Recently, the involvement of small molecules (e.g., aurovertins) in the interaction between nematodes and P. chlamydosporia has been demonstrated [19].

An active beauvericin has been extracted from culture filtrate of $B$. bassiana. This metabolite is a mycotoxin whose insecticidal properties have been previously reported (e.g., against the wheat aphid Schizaphis graminum at $0.5 \mathrm{mg} / \mathrm{mL}$ ) [20,21]. This molecule contains three residues, each with D-2-hydroxyisovaleric acid (Hiv) and L- $N$-methylphenylalanine linked alternately [21].

Destruxin B2 is the active molecule isolated from M. anisopliae extract. Destruxins exhibited a wide variety of biological activities, but are best known for their insecticidal and phytotoxic properties [22,23]. However, the effect of destruxin B2 against Acyrthosiphon pisum is reported here for the first time.

T. pinophilus strain F36CF produced 3-O-methylfunicone. This compound was downregulated in the presence of T. harzianum M10 [8], exhibited notable antibiotic and antitumor properties, and recently exhibited an insecticidal effect, thus expanding the biological activities of this compound [24]. Recently, talarodiolide, a new 12-membered macrodiolide, was isolated and characterized from the culture filtrate of a T. pinophilus strain [25]. This metabolite did not show insecticidal activity, highlighting that the strain collection is important to select the best producers of bioactive compounds.

\section{Materials and Methods}

Fungal strains. The microbes used in the present study were present in the fungal collection at Department of Agricultural Sciences, University of Naples Federico II (UNINA Collection) or isolated from different sources (Table 4). 
Table 4. Fungal strains used in the present study for the isolation of metabolites with insecticidal activity against the pea aphid $A$. pisum.

\begin{tabular}{ccccccc}
\hline Microbes & Strain & Division & Class & Order & Family & Habitat/Source * \\
\hline Beauveria bassiana & BB1 & Ascomycota & Sordariomycetes & Hypocreales & Cordycipitaceae & UNINA Collection \\
Chloridium virescens & F57 & Ascomycota & Sordariomycetes & Chaetosphaeriales & Chaetosphaeriaceae & Pasture \\
Metarhizium anisopliae & MA3 & Ascomycota & Sordariomycetes & Hypocreales & Clavicipitaceae & UNINA Collection \\
Paecilomyces lilacinus & 100379 & Ascomycota & Eurotiomycetes & Eurotiales & Trichocomaceae & UNINA Collection \\
Penicillium chrysogenum & F5 & Ascomycota & Eurotiomycetes & Eurotiales & Trichocomaceae & Mediterranean area \\
Penicillium decumbens & F29 & Ascomycota & Eurotiomycetes & Eurotiales & Trichocomaceae & Mediterranean area \\
Penicillium griseofulvum & F11 & Ascomycota & Eurotiomycetes & Eurotiales & Trichocomaceae & Mediterranean area \\
Penicillium restrictum & F55 & Ascomycota & Eurotiomycetes & Eurotiales & Trichocomaceae & Mediterranean area \\
Pochonia chlamydosporia & B & Ascomycota & Sordariomycetes & Hypocreales & Clavicipitaceae & UNINA Collection \\
Talaromyces pinophilus & F36CF & Ascomycota & Eurotiomycetes & Eurotiales & Trichocomaceae & Arbutus unedo \\
Trichoderma tomentosum & F19 & Ascomycota & Sordariomycetes & Hypocreales & Hypocreaceae & Woodland (Oak) \\
Trichoderma asperellum & CINO1 & Ascomycota & Sordariomycetes & Hypocreales & Hypocreaceae & UNINA Collection \\
Trichoderma harzianum & M10 & Ascomycota & Sordariomycetes & Hypocreales & Hypocreaceae & UNINA Collection \\
Trichoderma harzianum & F53 & Ascomycota & Sordariomycetes & Hypocreales & Hypocreaceae & Mediterranean area \\
Trichoderma velutinum & F28 & Ascomycota & Sordariomycetes & Hypocreales & Hypocreaceae & Woodland (Oak) \\
\hline
\end{tabular}

${ }^{*}$ UNINA Collection: fungal collection available at the Department of Agricultural Sciences/University of Naples Federico II, Naples, Italy.

The fungi were identified according to morphological features and molecular analyses. Briefly, an amount of $10^{6}$ spores $/ \mathrm{mL}$ was inoculated in a 250-mL Erlenmeyer Flasks containing $100 \mathrm{~mL}$ of sterile Potato Dextrose Broth (PDB, HIMEDIA, Mumbai, India). Each flask was incubated at $25^{\circ} \mathrm{C}$ in an orbital shaker (150 r.p.m.) and fungi were left to grow for seven days. Mycelium was recovered, ground to a powder in liquid nitrogen, and used to perform the DNA extraction. Genetic analysis was carried out through PCR and sequencing of the rDNA Internal Transcribed Spacer (ITS) and $\beta$-tubulin gene, using the most common primers to identify fungal strains: ITS1 and ITS4 [26], as well as tub2 and BenA [27]. The PCR products were subjected to gel electrophoresis, excised, and sequenced [26,27]. Analysis of the ITS gave $99 \%$ of identity with GenBank sequences of the fungi reported in Table 4, confirming the identity of the microbes.

Secondary metabolites production. The fungi were maintained on potato dextrose agar (PDA, HIMEDIA) at room temperature and sub-cultured bimonthly. Liquid cultures were prepared in 5000 L-Erlenmeyer flasks containing $1 \mathrm{~L}$ of PDB and inoculated with five mycelial plugs $\left(7 \mathrm{~mm}^{2}\right)$ from a fresh PDA culture of each fungal strain. After 30 days of incubation at $25{ }^{\circ} \mathrm{C}$ in static conditions, the cultures were filtered through filter paper (Whatman No. 4) and the filtrate was analyzed by LC-MS qTOF [28].

Extraction and isolation of fungal secondary metabolites. The culture filtrates were acidified to $\mathrm{pH} 4$ with $5 \mathrm{M} \mathrm{HCl}$ and extracted exhaustively with ethyl acetate (EtOAc). The combined organic extracts were dried $\left(\mathrm{Na}_{2} \mathrm{SO}_{4}\right)$ and solvent eliminated under reduced pressure at $35^{\circ} \mathrm{C}$ (Rotavapor $\mathrm{RV}$ $10 \mathrm{IKA}^{\circledR}$ - Werke GmbH \& Co. KG, Staufen, Germany). The residues recovered were fractionated by column chromatography (silica gel; $200 \mathrm{~g}$ ) eluted with different eluents (Table 5) and the homogeneous fractions were collected as reported in Table 5. For thin layer chromatography (TLC) the following solvents were used: dichloromethane $\left(\mathrm{CH}_{2} \mathrm{Cl}_{2}\right) /$ methanol $(\mathrm{MeOH})$ 90:10; 80:20 (v/v), chloroform $\left(\mathrm{CHCl}_{3}\right) / \mathrm{MeOH}$ 90:10; 80:20 (v/v); EtOAc/petroleum ether 90:10; 80:20 (v/v) [28]. All fractions were tested for insecticidal activity against $A$. pisum, and, where necessary, further purified by preparative TLC (Table 5). 
Table 5. List of solvents used for chromatographic separations (column chromatography or preparative TLC) and total number of homogeneous collected fractions.

\begin{tabular}{|c|c|c|}
\hline Fungal Source & $\begin{array}{l}\text { Eluent Used for Column Chromatography } \\
\text { and Preparative TLC * }\end{array}$ & $\begin{array}{l}\text { Total Number of } \\
\text { Homogeneous Fractions }\end{array}$ \\
\hline Paecilomyces lilacinus & EtOAc/petroleum ether (90:10, v:v) & 5 \\
\hline Penicillium griseofulvum & EtOAc/petroleum ether $(90: 10, \mathrm{v}: \mathrm{v})$ & 8 \\
\hline Pochonia chlamydosporia & $\begin{array}{l}\mathrm{CH}_{2} \mathrm{Cl}_{2} / \mathrm{MeOH}(90: 10, \mathrm{v}: \mathrm{v}) \text {; fraction No. } 4 \text { out } \\
\text { of } 5 \text { was further purified by preparative TLC on } \\
\text { silica gel with } \mathrm{CH}_{2} \mathrm{Cl}_{2} / \mathrm{MeOH}(90: 10, \mathrm{v}: \mathrm{v})\end{array}$ & 5 \\
\hline Beauveria bassiana & EtOAc/petroleum ether $(90: 10, \mathrm{v}: \mathrm{v})$ & 5 \\
\hline Metarhizium anisopliae & EtOAc/petroleum ether $(90: 10, \mathrm{v}: \mathrm{v})$ & 7 \\
\hline Talaromyces pinophilus & $\begin{array}{c}\mathrm{CH}_{2} \mathrm{Cl}_{2} / \mathrm{MeOH}(98: 2, \mathrm{v}: \mathrm{v}) \text {; Fraction No. } 2 \text { out } \\
\text { of } 7 \text { was further purified by preparative TLC } \\
\text { with } \mathrm{CH}_{2} \mathrm{Cl}_{2} / \mathrm{MeOH}(98: 2, \mathrm{v}: \mathrm{v})\end{array}$ & 7 \\
\hline
\end{tabular}

* EtOAc: ethyl acetate; $\mathrm{CH}_{2} \mathrm{Cl}_{2}$ : Dichloromethane; $\mathrm{MeOH}$ : Methanol.

General experimental procedures. The isolated molecules were solubilised in $700 \mu \mathrm{L}$ of deuterated chloroform (99.8\% $\mathrm{CDCl}_{3}$ - Sigma-Aldrich, Darmstadt, Germany) and transferred into a stoppered NMR tube ( $5 \mathrm{~mm}, 7^{\prime \prime}$, 507-HP-7, NORELL, Morganton, NC, USA) where remaining void volume was gently degassed by a $\mathrm{N}_{2}$ flux. Proton and carbon solvent signals were used as reference to calibrate both ${ }^{1} \mathrm{H}$ and ${ }^{13} \mathrm{C}$ frequency axes. A $400 \mathrm{MHz}$ Bruker Avance spectrometer (Bruker Co., Billerica, MA, USA), equipped with a $5 \mathrm{~mm}$ Bruker Broad Band Inverse probe (BBI), working at the ${ }^{1} \mathrm{H}$ and ${ }^{13} \mathrm{C}$ frequencies of 400.13 and $100.61 \mathrm{MHz}$, respectively, was used for the NMR measurements (at $25 \pm 1^{\circ} \mathrm{C}$ ).

Monodimensional ${ }^{1} \mathrm{H}$ and ${ }^{13} \mathrm{C}$ acquisitions were conducted as follows: proton spectra were acquired with $2 \mathrm{~s}$ of thermal equilibrium delay (number of scans $=64$ ), a $90^{\circ}$ pulse length $7.7 \mu \mathrm{s}$, 50 transients and $16 \mathrm{ppm}(6410.2 \mathrm{~Hz})$ as spectral widths, whereas proton-decoupled carbon acquisitions were executed by both inverse-gated and DEPT $135^{\circ}$ pulse sequences, adopting 7 and $5 \mathrm{~s}$ of equilibrium delay, 12,500 and 2400 transients, respectively, and a spectral width of $250 \mathrm{ppm}$ $(25.152 \mathrm{KHz})$. A time domain of 32,768 points was adopted for all cited mono-dimensional experiments. Homo-nuclear ${ }^{1} \mathrm{H}_{-}{ }^{1} \mathrm{H}$ COSY (COrrelation SpectroscopY), TOCSY (TOtal Correlation SpectroscopY), NOESY (Nuclear Overhauser Enhancement SpectroscopY), and hetero-nuclear ${ }^{1} \mathrm{H}-{ }^{13} \mathrm{C}$ HSQC (Hetero-nuclear Single-Quantum Correlation) and HMBC (Hetero-nuclear Multiple Bond Coherence) experiments (2D) were used for structural identification of metabolites. 2D homo- and heteronuclear spectra experiments were acquired with 48 and 80 scans, respectively, 16 dummy scans, a time domain of $2 \mathrm{k}$ points (F2) and 256 experiments (F1). TOCSY and NOESY experiments were conducted with a mixing time of 80 and $1000 \mathrm{~ms}$, respectively, while HSQC and HMBC experiments were optimized for $145 \mathrm{~Hz}$ short and $6.5 \mathrm{~Hz}$ long range $\mathrm{J}_{\mathrm{CH}}$ couplings, respectively. All executed 2D experiments were gradient enhanced, except for the TOCSY acquisition. A Qsine weighting function associated to a magnitude mode was used to process NOESY spectrum with the purpose to emphasize the weak cross-peaks and minimize the noise artefacts. The free induction decay (FID) of mono-dimensional spectra was multiplied by an exponential factor corresponding to $0.1 \mathrm{~Hz}$, for ${ }^{1} \mathrm{H}$ and ${ }^{13} \mathrm{C}$ acquisitions, and to $1 \mathrm{~Hz}$ for DEPT $135^{\circ}$ experiment. All above mentioned spectra were baseline corrected and processed by using Bruker Topspin Software (v.4.0.2).

LC-MS/MS Q-TOF analysis were done on an Agilent HP 1260 Infinity Series liquid chromatograph equipped with a DAD system (Agilent Technologies, Santa Clara, CA, USA) coupled to a Q-TOF mass spectrometer model G6540B (Agilent Technologies). Separations were performed on a Zorbax Eclips Plus C18 column, $4.6 \times 100 \mathrm{~mm}$, with $3.5 \mu \mathrm{m}$ particles (Agilent Technologies). The analyses were done at a constant temperature of $37^{\circ} \mathrm{C}$ and using a linear gradient system composed of $\mathrm{A}: 0.1 \%$ $(v / v)$ formic acid in water, and B: $0.1 \%(v / v)$ formic acid in acetonitrile. The flow was $0.6 \mathrm{~mL} / \mathrm{min}$, $95 \%$ A graduating to $100 \%$ B in $12 \mathrm{~min}, 100 \%$ B 12-15 min, 95\% A 15-17 and equilibrating 95\% A 17-20 min. The UV spectra were collected by DAD every $0.4 \mathrm{~s}$ from 190 to $750 \mathrm{~nm}$ with a resolution of 
$2 \mathrm{~nm}$. The MS system was equipped with a Dual Electrospray Ionization (ESI) source and operated with Agilent MassHunter Data Acquisition Software, rev. B.05.01 in the positive or negative mode. Mass spectra were recorded in the range $m / z 100-1600$ as centroid spectra, with 3 scans per second. Two reference mass compounds were used to perform the real-time lock mass correction, purine $\left(\mathrm{C}_{5} \mathrm{H}_{4} \mathrm{~N}_{4}\right.$ at $\left.m / z 121.050873,10 \mu \mathrm{mol} / \mathrm{L}\right)$ and hexakis $(1 \mathrm{H}, 1 \mathrm{H}, 3 \mathrm{H}$-tetrafluoropentoxy)-phosphazene $\left(\mathrm{C}_{18} \mathrm{H}_{18} \mathrm{O}_{6} \mathrm{~N}_{3} \mathrm{P}_{3} \mathrm{~F}_{24}\right.$ at $\mathrm{m} / z$ 922.009798, $\left.2 \mu \mathrm{mol} / \mathrm{L}\right)$. The capillary was maintained at $4000 \mathrm{~V}$, fragmentor voltage at $180 \mathrm{~V}$, cone 1 (skimmer 1) at $45 \mathrm{~V}$, Oct RFV at $750 \mathrm{~V}$. Gas temperature was $350{ }^{\circ} \mathrm{C}$ during the run at $11 \mathrm{~L} / \mathrm{min}$, and the nebulizer was set at 45 psig. The injected sample volume was $5 \mu \mathrm{L}$.

MS/MS spectra were simultaneously recorded for confirmation purposes of new compounds, using the operating parameters described above, unless otherwise stated. The instrument was operated in the range $m / z$ 100-1000, recording two spectra per second in targeted acquisition mode (targeted mass: $244.1197, Z=1$, RT $5.88 \pm 0.5 \mathrm{~min}$ ). The sample collision energy was set to $20 \mathrm{~V}$.

LC-MS data were evaluated using MassHunter Qualitative Analysis Software B.06.00 and compared to known compounds included in an in-house database. The database contains information of about 4000 known secondary metabolites isolated from more than 80 different fungal genera, and recorded according to their name, molecular formula, monoisotopic mass and producing organism. Positive identifications of fungal metabolites were reported if the compound was detected with a mass error below $10 \mathrm{ppm}$ and with a sufficient score. Standards were used to confirm the chemical identifications.

UV spectra were recorded with a V-730 UV-Visible Spectrophotometer JASCO (Mary's Court, Easton, MD, USA). Column chromatography was performed using silica gel (Merck silica gel $60 \mathrm{GF}_{254}$; Merck, Darmstadt, Germany), and TLC with glass pre-coated silica gel $\mathrm{GF}_{254}$ plates (Merck Kieselgel $60 \mathrm{GF}_{254}, 0.25 \mathrm{~mm}$ ). The compounds were detected on TLC plates using UV light (254 or $\left.366 \mathrm{~nm}\right)$ and/or by dipping the plates in a $5 \%(v / v) \mathrm{H}_{2} \mathrm{SO}_{4}$ solution in ethanol followed by heating at $110{ }^{\circ} \mathrm{C}$ for $10 \mathrm{~min}[28,29]$.

Acetylation of chlamyphilone. Acetic anhydride $(40 \mu \mathrm{L})$ was added to chlamyphilone $(\mathbf{1}, 2.5 \mathrm{mg})$, dissolved in dry pyridine ( $80 \mu \mathrm{L} 2.5 \mathrm{mg}$ ), and the residue was purified by preparative TLC on silica gel (petroleum ether/aceton, 20:80, $v / v)$ to yield the acetyl derivative $6(1.4 \mathrm{mg}, 49 \%)$ [29]. The reaction was monitored by LC-MS analysis (Figure S1).

In vivo insecticidal assay. Insecticidal activity of organic extracts, each column fraction and pure metabolites were tested against the pea aphid Acyrthosiphon pisum. Aphids were reared on Vicia faba var. aguadulce in a growth chamber $\left(20 \pm 1{ }^{\circ} \mathrm{C}, 70 \% \mathrm{RH}, 18 \mathrm{~h}\right.$ light $/ 6 \mathrm{~h}$ dark photoperiod). Small populations were synchronized to obtain newborn nymphs every $24 \mathrm{~h}$. Third-instar nymphs were dipped in the assay solution for $10 \mathrm{~s}$ and put on a paper towel to dry. Then, each insect was carefully transferred by a soft paintbrush on a leaf plug [30,31]. Twenty treated (or untreated-solvent control) 3rd-instar nymphs were placed on two circular (35 mm diameter) leaf plugs on $2 \%$ water agar layer in a Petri dish, in order to keep the leaf turgid. Plates were incubated at the climatic conditions described above and the number of dead aphids was assessed 24, 48, and $72 \mathrm{~h}$ after treatments. Extracts, fractions, and pure compounds were tested at 500, 400, 300, 200, 100, and $50 \mu \mathrm{g} / \mathrm{mL}$. Each metabolite solution was also tested for phytotoxicity on $V$. faba. The aphid mortality has been calculated in each treatment as the mean value \pm standard deviation, in three replicates for each time point $(24,48$, and $72 \mathrm{~h}$ ). The experiments were repeated at least twice.

Statistical analysis. Data analysis was performed with SPSS 11.0 software (Statistics for Windows Version 24.0, IBM Corp., Armonk, NY, USA), and statistical analysis was done using one-way analysis of variance (ANOVA). The Least Significant Difference (LSD) post hoc test with $p<0.05$ was used to analyse the multiple comparisons. The mean values between different treatments at the same time point and the mean values between the same treatments at different time points were compared. 


\section{Conclusions}

In this work six known metabolites with activity against the pea aphid A. pisum have been isolated from culture filtrates of selected fungal strains; for some of them this is the first report of insecticidal activity (Table S1). Moreover, a novel anti-aphid natural product, named chlamyphilone, has been isolated form the culture filtrate of $P$. chlamydosporia and fully characterized. The isolation of natural products with beneficial effects for plants may help to formulate novel secondary metabolites-based biopesticides, which represent promising alternatives to synthetic chemicals in agriculture. Further investigations should optimize extraction protocols and define environmental parameters that can affect the commercial formulations based on these natural compounds.

Supplementary Materials: The following are available online, Figures S1-S11 and S13-S14: NMR and MS spectra of compounds. Figure S12: Conformational model of the new compound named chlamyphilone. Table S1: Biological activity of the isolated compounds.

Author Contributions: F.V. and F.L. conceived the experiments and analyzed all the results. R.M. analyzed all the results and characterized the fungal strains. M.C.D. and M.G. conducted with F.L. the experiments on insects. M.L., P.C., F.L., and S.L.W. conducted the experiments with fungal strains. P.M., A.P. and F.V. characterized all the isolated metabolites. All authors reviewed the manuscript.

Funding: This work was supported by the following projects: MIUR-PON [grant number Linfa 03PE_00026_1], [grant number Marea 03PE_00106].

Conflicts of Interest: The authors declare no conflicts of interest.

\section{References}

1. Dayan, F.E.; Cantrell, C.L.; Duke, S.O. Natural products in crop protection. Bioorg. Med. Chem. 2009, 17, 4022-4034. [CrossRef] [PubMed]

2. Copping, L.G.; Duke, S.O. Natural products that have been used commercially as crop protection agents. Pest Manag. Sci. 2007, 63, 524-554. [CrossRef] [PubMed]

3. Saxena, S.; Pandey, A.K. Microbial metabolites as eco-friendly agrochemicals for the next millennium. Appl. Microbiol. Biot. 2001, 55, 395-403. [CrossRef]

4. Tanaka, Y.; Omura, S. Agroactive compounds of microbial origin. Annu. Rev. Microbiol. 1993, 47, 57-87. [CrossRef] [PubMed]

5. Berdy, J. Bioactive microbial metabolites. J. Antibiot. 2005, 58, 1-26. [CrossRef] [PubMed]

6. Vinale, F.; Sivasithamparam, K.; Ghisalberti, E.L.; Ruocco, M.; Woo, S.; Lorito, M. Trichoderma secondary metabolites that affect plant metabolism. Nat. Prod. Commun. 2012, 7, 1545-1550. [PubMed]

7. Mukherjee, P.K.; Horwitz, B.A.; Kenerley, C.M. Secondary metabolism in Trichoderma-A genomic perspective. Microbiology 2012, 158, 35-45. [CrossRef] [PubMed]

8. Vinale, F.; Nicoletti, R.; Borrelli, F.; Mangoni, A.; Parisi, O.A.; Marra, R.; Lombardi, N.; Lacatena, F.; Grauso, L.; Finizio, S.; et al. Co-culture of plant beneficial microbes as source of bioactive metabolites. Sci. Rep. 2017, 7, 14330. [CrossRef] [PubMed]

9. Digilio, M.C.; Mancini, E.; Voto, E.; De Feo, V. Insecticide activity of mediterranean essential oils. J. Plant Interact. 2008, 3, 17-23. [CrossRef]

10. Fukushima, K.; Arai, T.; Mori, Y.; Tsuboi, M.; Suzuki, M. Studies on peptide antibiotics, leucinostatins. J. Antibiot. 1983, 36, 1613-1630. [CrossRef] [PubMed]

11. Park, J.O.; Hargreaves, J.R.; McConville, E.J.; Stirling, G.R.; Ghisalberti, E.L.; Sivasithamparam, K. Production of leucinostatins and nematicidal activity of Australian isolates of Paecilomyces lilacinus (Thom) Samson. Lett. Appl. Microbiol. 2004, 38, 271-276. [CrossRef] [PubMed]

12. Oxford, A.E.; Raistrick, H.; Simonart, P. Studies in the biochemistry of micro-organisms: Griseofulvin, $\mathrm{C}_{17} \mathrm{H}_{17} \mathrm{O}_{6} \mathrm{Cl}$, a metabolic product of Penicillium griseofulvum Dierckx. Biochem. J. 1939, 33, 240. [CrossRef] [PubMed]

13. Banani, H.; Marcet-Houben, M.; Ballester, A.R.; Abbruscato, P.; González-Candelas, L.; Gabaldón, T.; Spadaro, D. Genome sequencing and secondary metabolism of the postharvest pathogen Penicillium griseofulvum. BMC Genom. 2016, 17, 19. [CrossRef] [PubMed] 
14. Dowd, P.F. Toxicity of the fungal metabolite griseofulvin to Helicoverpa zea and Spodoptera frugiperda. Entomol. Exp. Appl. 1993, 69, 5-11. [CrossRef]

15. Kimura, Y.; Shimada, A.; Kusano, M.; Yoshii, K.; Morita, A.; Nishibe, M.; Fujiok, S.; Kawano, T. Myxostiolide, myxostiol, and clavatoic acid, plant growth regulators from the fungus Myxotrichum stipitatum. J. Nat. Prod. 2002, 65, 621-623. [CrossRef] [PubMed]

16. Osmanova, N.; Schultze, W.; Ayoub, N. Azaphilones: A class of fungal metabolites with diverse biological activities. Phytochem. Rev. 2010, 9, 315-342. [CrossRef]

17. Gao, J.; Yang, S.; Qin, J. Azaphilones: Chemistry and Biology. Chem. Rev. 2013, 113, 4755-4811. [CrossRef] [PubMed]

18. Akihisa, T.; Tokuda, H.; Yasukawa, K.; Ukiya, M.; Kiyota, A.; Sakamoto, N.; Suzuki, T.; Tanabe, N.; Nishino, H. Azaphilones, furanoisophthalides, and amino acids from the extracts of Monascus pilosus-fermented rice (red-mold rice) and their chemopreventive effects. J. Agric. Food Chem. 2005, 53, 562-565. [CrossRef]

19. Wang, Y.L.; Li, L.F.; Li, D.X.; Wang, B.; Zhang, K.; Niu, X. Yellow pigment aurovertins mediate interactions between the pathogenic fungus Pochonia chlamydosporia and its nematode host. J. Agric. Food Chem. 2015, 63, 6577-6587. [CrossRef]

20. Logrieco, A.; Moretti, A.; Castella, G.; Kostecki, M.; Golinski, P.; Ritieni, A.; Chelkowski, J. Beauvericin production by Fusarium Species. Appl. Environ. Microbiol. 1998, 64, 3084-3088.

21. Daniel, J.F.; Silva, A.A.; Nakagawa, D.H.; de Medeiros, L.S.; Carvalho, M.G.; Tavarres, L.J.; Abreud, L.M.; Filhob, E.R. Larvicidal activity of Beauveria bassiana extracts against Aedes aegypti and identification of Beauvericins. J. Braz. Chem. Soc. 2017, 28, 1003-1013. [CrossRef]

22. Soledade, M.; Pedras, C.; Zaharia, L.I.; Ward, D.E. The destruxins: Synthesis, biosynthesis, biotransformation, and biological activity. Phytochemistry 2002, 59, 579-596.

23. Zhang, H.; Hu, W.; Xiao, M.; Ou, S.; Hu, Q. Destruxin A induces and binds HSPs in Bombyx mori Bm12 cells. J. Agric. Food Chem. 2017, 65, 9849-9853. [CrossRef] [PubMed]

24. Vinale, F.; Nicoletti, R.; Lacatena, F.; Marra, R.; Sacco, A.; Lombardi, N.; d’Errico, G.; Digilio, M.C.; Lorito, M.; Woo, S.L. Secondary metabolites from the endophytic fungus Talaromyces pinophilus. Nat. Prod. Res. 2017, 31, 1778-1785. [CrossRef] [PubMed]

25. Salvatore, M.M.; Della Greca, M.; Nicoletti, R.; Salvatore, F.; Vinale, F.; Naviglio, D.; Andolfi, A. Talarodiolide, a new 12-membered macrodiolide, and GC/MS Investigation of culture filtrate and mycelial extracts of Talaromyces pinophilus. Molecules 2018, 23, 950. [CrossRef] [PubMed]

26. Manter, D.K.; Vivanco, J.M. Use of the ITS primers, ITS1F and ITS4, to characterize fungal abundance and diversity in mixed-template samples by qPCR and length heterogeneity analysis. J. Microbiol. Methods 2007, 71, 7-14. [CrossRef] [PubMed]

27. Glass, N.L.; Donaldson, G.C. Development of Primer Sets Designed for Use with the PCR To Amplify Conserved Genes from Filamentous Ascomycetes. Appl. Environ. Microbiol. 1995, 61, 1323-1330.

28. Vinale, F.; Strakowska, J.; Mazzei, P.; Piccolo, A.; Marra, R.; Lombardi, N.; Manganiello, G.; Pascale, A.; Woo, S.L.; Lorito, M. Cremenolide, a new antifungal, 10-member lactone from Trichoderma cremeum with plant growth promotion activity. Nat. Prod. Res. 2016, 30, 2575-2581. [CrossRef]

29. Vinale, F.; Arjona Girona, I.; Nigro, M.; Mazzei, P.; Piccolo, A.; Ruocco, M.; Woo, S.; Ruano Rosa, D.; López Herrera, C.; Lorito, M. Cerinolactone, a hydroxy-lactone derivative from Trichoderma cerinum. J. Nat. Prod. 2011, 75, 103-106. [CrossRef]

30. De Feo, V.; Mancini, E.; Voto, E.; Curini, M.; Digilio, M.C. Bioassay-oriented isolation of an insecticide from Ailanthus altissima. J. Plant Interact. 2009, 4, 119-123. [CrossRef]

31. Chandrasena, D.; Difonzo, C.; Byrne, A. An Aphid-Dip Bioassay to Evaluate Susceptibility of Soybean Aphid (Hemiptera: Aphididae) to Pyrethroid, Organophosphate, and Neonicotinoid Insecticides. J. Econ. Entomol. 2011, 104, 1357-1363. [CrossRef] [PubMed]

Sample Availability: Samples of the compounds 1-9 are available from the authors. 